\title{
Spermatozoa telomeres determine telomere length in early embryos and offspring
}

\author{
C de Frutos, A P López-Cardona, N Fonseca Balvís, R Laguna-Barraza, D Rizos, \\ A Gutierrez-Adán and P Bermejo-Álvarez \\ Instituto Nacional de Investigación y Tecnología Agraria y Alimentaria, Avenida Puerta de Hierro 12 local 10, \\ 28040 Madrid, Spain \\ Correspondence should be addressed to P Bermejo-Álvarez; Email: borrillobermejo@hotmail.com
}

\begin{abstract}
Offspring telomere length (TL) has been correlated with paternal $T L$, but the mechanism for this parent of origin-specific inheritance remains unclear. The objective of this study has been to determine the role of spermatozoa TL in embryonic telomere lengthening by using two mouse models showing dimorphism in their spermatozoa TL: Mus musculus vs Mus spretus and old vs young Mus musculus. Mus spretus spermatozoa displayed a shorter TL than Mus musculus. Hybrid offspring exhibited lower TL compared with Mus musculus starting at the two-cell stage, before the onset of telomerase expression. To analyze the role of spermatozoa telomeres in early telomere lengthening, we compared the TL in oocytes, zygotes, two-cell embryos and blastocysts produced by parthenogenesis or by fertilization with Mus musculus or Mus spretus spermatozoa. TL was significantly higher in spermatozoa compared with oocytes, and it increased significantly from the oocyte to the zygote stage in those embryos fertilized with Mus musculus spermatozoa, but not in those fertilized with Mus spretus spermatozoa or produced by parthenogenesis. A further increase was noted from the zygote to the two-cell stage in fertilized Mus musculus embryos, whereas hybrid embryos maintained the oocyte TL. Spermatozoa TL shortened with age in Mus musculus and the offspring from young males showed a significantly higher TL compared with that fathered by old males. These significant differences were already noticeable at the two-cell stage. These results suggest that spermatozoa telomeres act as a guide for telomerase-independent telomere lengthening resulting in differences in TL that persist after birth.

Free Spanish abstract: A Spanish translation of this abstract is freely available at http://www.reproduction-online.org/content/151/1/1/ suppl/DC1.

Reproduction (2016) 151 1-7
\end{abstract}

\section{Introduction}

Telomeres are repetitive DNA sequences situated at chromosome ends that exert a predominant role in DNA protection (de Lange 2005). In somatic cells, telomeres shorten in every cell cycle and thus, telomere length (TL) determines the number of cell divisions before senescence. The importance of its protective role on the maintenance of genomic integrity is manifested by the association of several disorders with telomere dysfunction. Short telomeres or telomere attrition has been linked to cancer, dyskeratosis congenita, aplastic anemia, ataxia telangiectasia, Werner syndrome, Bloom syndrome, Fanconi anemia and Duchenne muscular dystrophy (Heiss et al. 1998, Oeseburg et al. 2010, Armanios \& Blackburn 2012, Calado \& Young 2012, Mourkioti et al. 2013).

In humans, offspring TL correlates strongly with paternal TL (Njajou et al. 2007, Atzmon et al. 2010), but the mechanisms responsible for this correlation remain unclear. In some cases, the paternal effect can be attributed to different haplotypes of TERT, a component of telomerase, the enzyme responsible for telomere lengthening (Atzmon et al. 2010). However, if that was the general case, a similar heritability of TL should be expected from the paternal or maternal side, but paternal TL consistently show a stronger positive correlation with offspring TL compared with maternal TL (De Meyer et al. 2007, Njajou et al. 2007). Furthermore, offspring TL has also been linked to paternal age in mixed populations (Unryn et al. 2005, De Meyer et al. 2007, Kimura et al. 2008, Eisenberg et al. 2012), an approach that excludes the effect of different haplotypes, as similar haplotype frequencies are expected across groups of different ages. In these cases, the effect of paternal age seems to be mediated by the TL of the spermatozoa, as telomeres are longer in both spermatozoa and the offspring of old men compared to young men (Allsopp et al. 1992, Baird et al. 2006, Kimura et al. 2008). However, the notion that spermatozoa TL determine offspring TL currently lacks a mechanistic support. 
TL has been proposed to be established during early preimplantation development, in the morula-to-blastocyst transition by a telomerase-dependent mechanism (Schaetzlein et al. 2004), and thereby without a role of spermatozoa TL. However, telomerase-null mice elongate their telomeres during the first embryonic cleavage division, well before the onset of telomerase expression, occurring in morula (Liu et al. 2007). This telomerase-independent elongation may occur by an alternative recombination based mechanism (Bryan et al. 1995), providing a molecular explanation of the effect of spermatozoa TL on the newborn TL, as the spermatozoon telomeres may act as a recombination template for oocyte telomeres. To test this possibility, we have analyzed the TL of preimplantation embryos in two models showing dimorphism in their spermatozoa TL: i) Mus musculus vs Mus spretus males and ii) old vs young Mus musculus males.

\section{Results}

In order to use a systems biology approach with substantial differences in TL between males, we fertilized Mus musculus oocytes with spermatozoa from two mouse species displaying a wide dimorphism in TL (Mus musculus and Mus spretus). As expected based on the well-known differences in telomeres observed in somatic cells (Kipling \& Cooke 1990, Starling et al. 1990), the spermatozoa TL was significantly longer in Mus musculus males compared to Mus spretus (Fig. 1A). Natural breeding between Mus spretus males and Mus musculus females resulted in offspring with a shorter TL compared with age-matched pure Mus musculus, but significantly longer than Mus spretus (Fig. 1B). These differences were already established at the blastocyst stage (Fig. 1C), when TL is thought to be set by the expression of telomerase (Schaetzlein et al. 2004).

Subsequently, we determined whether a telomeraseindependent mechanism played a role in the differences in embryonic TL by analyzing the changes in TL before embryonic genome activation occurs in embryos produced with spermatozoa carrying long telomeres (Mus musculus), short telomeres (Mus spretus) or produced by parthenogenesis (i.e., diploid embryos with genomes derived exclusively from maternal oocyte - origin). A preliminary experiment observed that the sample collection protocol lead to similar DNA content (quantified by Rn18S) in oocytes, zygotes and two-cell embryos samples (Fig. 2A), allowing TL quantification by absolute qPCR. TL increased significantly from the oocyte to the zygote stage in fertilized Mus musculus embryos, but this increase was not noticed in parthenogenetic Mus musculus or embryos produced with spermatozoa with short telomeres (Mus spretus), suggesting that the telomeres in Mus musculus spermatozoa are longer than those present in the oocyte chromosomes (Fig. 2B). This hypothesis was confirmed

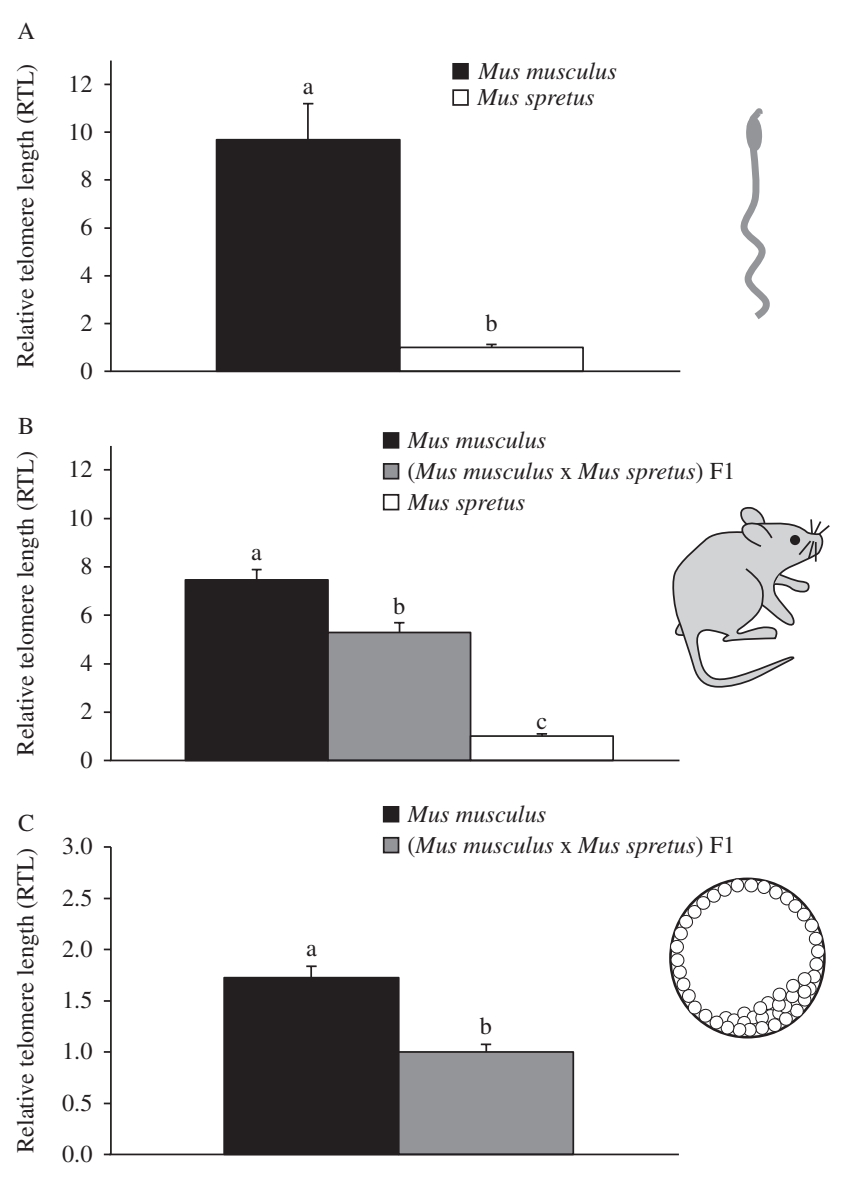

Figure 1 Telomere length in spermatozoa, offspring and embryos from Mus musculus and Mus spretus. (A) Relative telomere length in spermatozoa; (B) Relative telomere length in offspring; (C) Relative telomere length in blastocysts. Different letters indicate significant differences based on ANOVA $(P \leq 0.05)$.

by comparing TL between Mus musculus spermatozoa and oocytes, which were found to be significantly longer in spermatozoa (Fig. 2C). At the two-cell stage, a further increase in TL occurs in fertilized Mus musculus embryos. In contrast, fertilized hybrid embryos maintained the TL of the oocyte, whereas parthenogenetic embryos increase their $\mathrm{TL}$, although to a lesser extent than their fertilized counterparts (Fig. 2B).

Finally, we sought to determine whether the smaller differences in TL occurring between Mus musculus males at different ages played a role on offspring TL. The analysis of TL in mouse spermatozoa obtained from males of different ages revealed that, contrary to the situation observed in humans, spermatozoa telomere shorten with age (Fig. 3A), following the same tendency as somatic cells. Then, we analyzed whether these differences occurring in spermatozoa resulted in different $T L$ in embryos and offspring. TL was significantly higher in two-cell embryos fathered by young males compared with those fathered by old males (Fig. 3B). Consistently, relative $\mathrm{TL}$ was significantly 

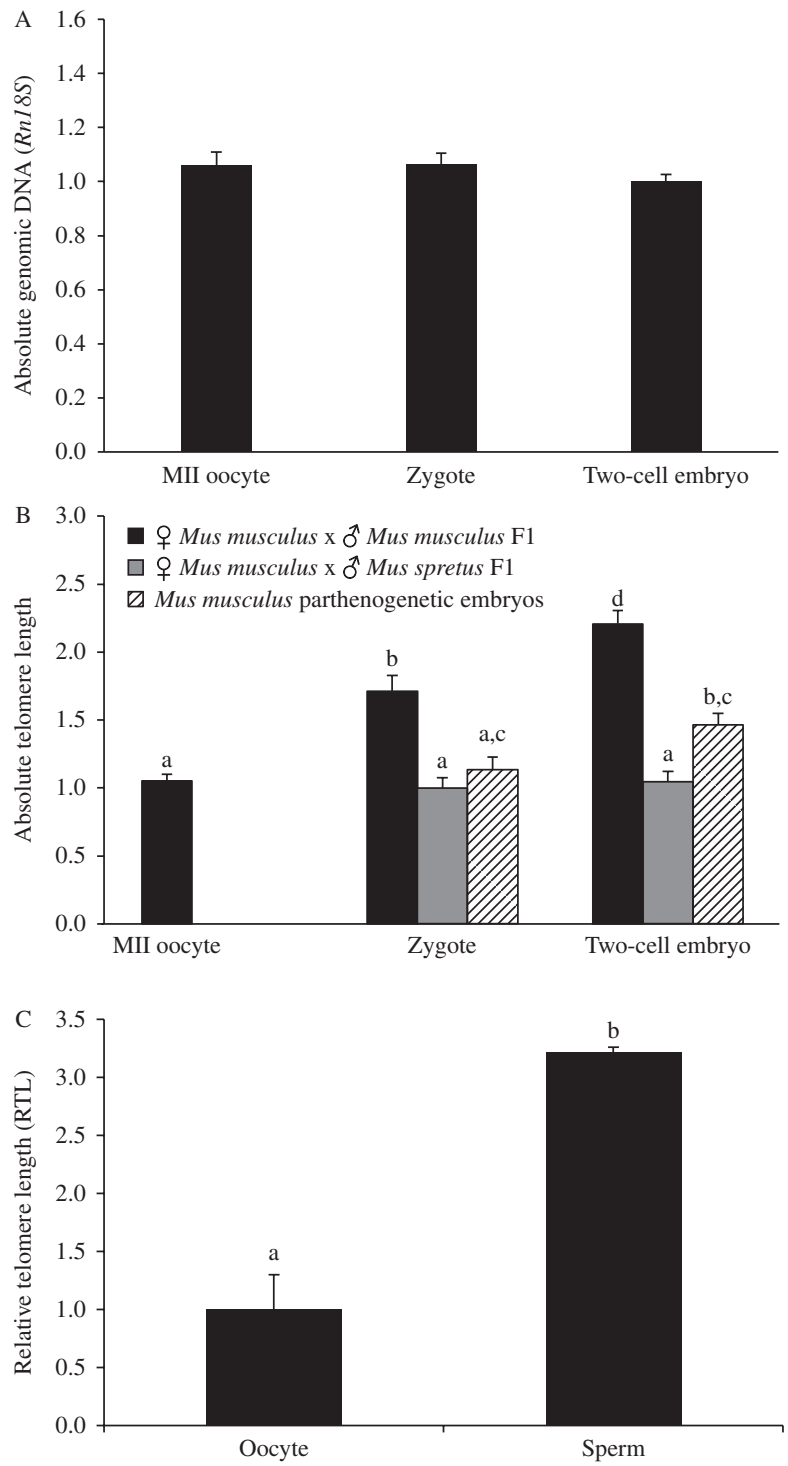

Figure 2 (A) Absolute genomic DNA quantification in Mus musculus oocytes, zygotes and two-cell embryo samples; (B) Absolute telomere length in Mus musculus oocytes and zygotes and two-cell embryos obtained by fertilization with Mus musculus or Mus spretus spermatozoa or by parthenogenetic activation; (C) Relative telomere length in Mus musculus oocytes and spermatozoa. Different letters indicate significant differences based on ANOVA $(P \leq 0.05)$.

higher in pups fathered by young males compared with those produced by old males (Fig. 3C).

\section{Materials and methods}

Unless otherwise stated, all chemicals were purchased from Sigma Chemical Co.

\section{Mice}

All experimental procedures were approved by the INIA ethical committee in animal research, according to European legislation. All mice used in this experiment were maintained in an animal facility with controlled temperature and photoperiod $\left(23 \pm 1{ }^{\circ} \mathrm{C}\right.$ and a ratio of $14 \mathrm{~h}$ light: $10 \mathrm{~h}$ darkness) with regular access to water and food and allowed to feed and drink ad libitum.

\section{Production of mouse embryos}

Mus musculus and Mus musculus $\times$ Mus spretus F1 embryos were obtained by IVF following a previously described method with minor modifications (Martín-Coello et al. 2008). Spermatozoa were collected from the epididymis of either young ( 3 months) or old (1 year) Mus musculus C57CBAF1 mature fertile males or Mus spretus males and were pre-incubated in a $500 \mu \mathrm{l}$ drop of human tubular fluid (HTF) (Quinn et al. 1985) medium supplemented with $2 \mathrm{mg} / \mathrm{ml} \mathrm{BSA}$ under oil at $37^{\circ} \mathrm{C}$ in $5 \% \mathrm{CO}_{2}$ /air for $15 \mathrm{~min}$ to allow sperm dispersion. Cumulus oocyte complexes were obtained from superovulated Mus musculus C57CBAF1 females (8-10 weeks old). Hormonal treatment consisted of an i.p. injection of $7.5 \mathrm{IU}$ of equine


Figure 3 Telomere length in spermatozoa, offspring and embryos obtained from young and old Mus musculus fathers. (A) Relative telomere length in spermatozoa; (B) Absolute telomere length in twocell embryos; (C) Relative telomere length in the offspring. Different letters indicate significant differences based on ANOVA $(P \leq 0.05)$. 
chorionic gonadotrophin (Folligon 500, Intervet) followed by $7.5 \mathrm{IU}$ of hCG (Veterin Corion, Equinvest) 48 h later. Females were euthanized $14 \mathrm{~h}$ after hCG injection, their oviducts were removed and cumulus oocyte complexes were recovered from the ampulla, washed in HTF and co-incubated with spermatozoa at a final concentration of $1 \times 10^{6} \mathrm{spermatozoa} / \mathrm{ml}$ in $500 \mu \mathrm{l}$ of HTF medium for $4-5 \mathrm{~h}$ at $37^{\circ} \mathrm{C}$ in $5 \% \mathrm{CO}_{2}$ in humidity saturated air. After IVF, the remaining cumulus cells and attached spermatozoa were removed by gentle pipetting, and the presumptive zygotes were washed in M2 medium before being placed in $30 \mu \mathrm{l}$ of KSOM media (Millipore) at $37^{\circ} \mathrm{C}$ in a humidified atmosphere of $5 \% \mathrm{CO}_{2}$ in air. The protocol yielded better results $(\sim 80 \%$ cleavage $)$ with Mus musculus sperm compared with Mus spretus ( $\sim 30 \%$ cleavage), probably due to the protocol being optimized for Mus musculus spermatozoa.

Parthenogenetic embryos were obtained from mature oocytes collected $16 \mathrm{~h}$ after hCG injection as previously described (Kishigami \& Wakayama 2007). Cumulus cells were dispersed in hyaluronidase solution and matured oocytes were activated by incubation in KSOM media supplemented with $10 \mathrm{mM} \mathrm{SrCl}_{2}, 2 \mathrm{mM}$ EDTA and $5 \mu \mathrm{g} / \mathrm{ml}$ cytochalasin B for 6 h (Kishigami \& Wakayama 2007). After activation, oocytes were washed three times and then cultured in KSOM as described above.

\section{Absolute TL evaluation in oocytes, zygotes and two-cell embryos}

The differences in TL between oocytes, zygotes and two-cell embryos produced by IVF with semen from Mus musculus or Mus spretus or parthenogenesis were analyzed in $\sim 30-40$ samples per stage by absolute qPCR. The low amount of DNA in these samples precludes the use of relative qPCR (i.e., data normalization to an internal control). Absolute qPCR consisted of the direct comparison of cycle threshold $(C \mathrm{t})$ values between samples without data normalization to an internal control. The method is in essence the same as absolute qPCR by a standard curve, but, for clearer representation, the data were normalized to the group with the highest average $C$ t (i.e., shortest $T L$ ), following the method for $\Delta C$ t described by (Schmittgen \& Livak 2008). By this approach, the data represents the fold change in $T L$ relative to the group exhibiting the shortest $T L$, whose fold-change value is 1 , consistent with the data obtained by relative TL quantification. As absolute qPCR requires equal amounts of starting DNA and to compensate for the differences in ploidy between the different stages, zona-free oocytes, zygotes and one-cell parthenotes were frozen in groups of two (4c, excluding polar body/ies) and two-cell embryos were individually stored (4c). In order to test that this sample collection protocol lead to similar DNA content in all samples, 20 additional samples of IVF-derived Mus musculus oocytes, zygotes and two-cell embryos were collected for genomic DNA quantification by qPCR as described below. Metaphase II oocytes were collected from the ampullae 19-20 h after hCG injection and had their cumulus cells removed by incubation in M2 media supplemented with hyaluronidase $(300 \mu \mathrm{g} / \mathrm{ml})$. Zygotes were identified by the presence of two visible pronuclei and collected $10 \mathrm{~h}$ after IVF or $8 \mathrm{~h}$ after oocyte activation. Two-cell embryos were collected at 1.5 day of culture. In all cases, the zona pellucida was removed by incubating oocytes and embryos into a Tyrode's acidic solution at $37^{\circ} \mathrm{C}$ for $30 \mathrm{~s}$, in order to remove possible attached spermatozoa and polar bodies and to increase digestion efficiency. Zona pellucida-free oocytes and embryos were washed three times in PBS, snap-frozen in liquid nitrogen in $0.1 \mathrm{ml}$ qPCR tubes (Corbett Research, Sydney, Australia) and stored at $-80^{\circ} \mathrm{C}$ until further analysis.

Samples were digested at $55^{\circ} \mathrm{C}$ overnight with $8 \mu \mathrm{l}$ of a $100 \mu \mathrm{g} / \mathrm{ml}$ proteinase $\mathrm{K}$ solution followed by proteinase $\mathrm{K}$ inactivation at $95{ }^{\circ} \mathrm{C}$ for $10 \mathrm{~min}$. The total digested sample $(8 \mu \mathrm{l})$ was used to analyze TL by absolute quantification by qPCR in oocytes, zygotes and two-cell embryos samples using primers specifically designed for the telomere sequence (Cawthon 2002) (Table 1). Genomic DNA quantification was conducted in independent samples by absolute quantification of the genomic sequence Rn18S by qPCR, following the same sample digestion and cycling conditions than absolute TL quantification. qPCR was performed using a Rotorgene 6000 Real Time Cycler (Corbett Research) $\left(94^{\circ} \mathrm{C} 3 \mathrm{~min}\right.$ followed by 40 cycles of $94^{\circ} \mathrm{C} 10 \mathrm{~s}, 60^{\circ} \mathrm{C} 30 \mathrm{~s}$ and $72{ }^{\circ} \mathrm{C}$ $30 \mathrm{~s})$. The absolute $\mathrm{Ct}$ value was normalized to the highest $\mathrm{Ct}$ observed value.

\section{Relative TL evaluation in spermatozoa, oocytes, blastocysts and tissue samples}

The relative TL in sperm was determined on samples from five adult Mus spretus and five adult Mus musculus males. Spermatozoa were collected in M2 media from the cauda epididymis. Sperm cell concentration was determined and $5 \times$ $10^{6}$ spermatozoa were frozen after centrifugation and removal of the supernatant. To compare relative TL between Mus musculus spermatozoa and oocytes, three groups of 50 oocytes were obtained from superovulated Mus musculus females as previously described, and their TL compared with those from three groups of $\sim 200$ spermatozoa. Spermatozoa and oocytes DNA was obtained after overnight digestion in $30 \mu \mathrm{l}$ of proteinase $\mathrm{K}(1.25 \mu \mathrm{g} / \mu \mathrm{l})$ in Tris $\mathrm{NaCl}$ EDTA buffer (STE) and $5 \mu \mathrm{l}$ of $0.1 \mathrm{M}$ dithiothreitol (DTT) at $55^{\circ} \mathrm{C}$ followed

Table 1 Sequences of primers and amplicon size of the qPCR used for telomere length determination.

\begin{tabular}{|c|c|c|c|}
\hline Gene & Primer sequence $\left(5^{\prime}-3^{\prime}\right)$ & Fragment size $(b p)$ & Gene Bank accession no. \\
\hline Telomere & $\begin{array}{l}\text { F:CGGTTTGTTTGGGTTTGGGTTTGGGTTTGGGTTTGGGTT } \\
\text { R:GGCTTGCCTTACCCTTACCСTTACCCTTACCCTTACCCT }\end{array}$ & 79 & NT_039202.7 \\
\hline Rn18s & $\begin{array}{l}\text { F:AGAAACGGCTACCACATCCAA } \\
\text { R:CCTGTATTGTTATTTTTCGTCACTACCT }\end{array}$ & 91 & NR_003278.1 \\
\hline Env4 & $\begin{array}{l}\text { F:TGCTTGGGCTCAGCAACATGG } \\
\text { R:GACAGAATGCCTCATCTATCGT }\end{array}$ & 260 & Y12713 \\
\hline
\end{tabular}


by phenol/chloroform extraction and then followed by isopropanol precipitation.

Blastocysts of Mus musculus embryos and hybrid Mus spretus (20 per group) were transferred into acidic tyrode to remove the zona pellucida and any attached spermatozoa. They were then washed three times in PBS and individually snap-frozen in liquid nitrogen in $0.2 \mu \mathrm{l}$ Eppendorf tubes and stored at $-80{ }^{\circ} \mathrm{C}$ until analysis. Samples were digested with $8 \mu \mathrm{l}$ of a $100 \mu \mathrm{g} / \mathrm{ml}$ proteinase K (Sigma, P8044) solution at $55{ }^{\circ} \mathrm{C}$ overnight. After digestion, proteinase $\mathrm{K}$ was inactivated at $95{ }^{\circ} \mathrm{C}$ for $10 \mathrm{~min}$ and $2 \mu \mathrm{l}$ of the digested sample were used for qPCR as described below.

Renal tissue was collected post-mortem from five male and five female adult Mus musculus (C57BL/6J), Mus spretus (ESPRET/Ei) and hybrid Mus spretus (C57BL/6J x ESPRET/Ei) mice and were frozen until further analysis. A tail biopsy was obtained from the offspring of old and young Mus musculus males 10 days after birth. Telomeres have been reported to shorten at equivalent rates in somatic tissues of adults (Daniali et al. 2013). Genomic DNA was extracted from these samples according to standard protocols. Briefly, $30 \mu \mathrm{l}$ of a dilution of proteinase $\mathrm{K}(1.25 \mu \mathrm{g} / \mathrm{ul})$ in STE buffer was added to the frozen samples, incubated at $55{ }^{\circ} \mathrm{C}$ overnight, then cooled to $4{ }^{\circ} \mathrm{C}$ and diluted in a final volume of $300 \mu$ l of DNase-free water. After digestion, genomic DNA was extracted using a phenolchloroform protocol followed by isopropanol precipitation and the pellet dissolved in $200 \mu \mathrm{l}$ of DNase-free water and then diluted to a final concentration of $50 \mathrm{ng} / \mu \mathrm{l}$.

Relative TL was determined using a real-time quantitative PCR method previously described (Cawthon 2002), which amplifies telomeric DNA with specially designed primers, with minor modifications (Bermejo-Alvarez et al. 2008). The values of telomere repeats were normalized to the amount of DNA present in the sample (determined by the amount of the multicopy gene $R n 18 S$ ) by the comparative Ct method. For relative TL analysis in oocytes and spermatozoa, the multi-copy gene Env4 was used to normalize to the amount of DNA instead of $R n 18 S$, as preliminary experiments yielded better amplification efficiencies for Env4 in low-DNA concentrations. Two microliter of the extracted DNA were used for each $20 \mu \mathrm{l}$ qPCR reaction using a Rotorgene 2000 Real Time Cycler (Corbett Research) $\left(94^{\circ} \mathrm{C} 3\right.$ min followed by 40 cycles of $94{ }^{\circ} \mathrm{C}$ $10 \mathrm{~s}, 60{ }^{\circ} \mathrm{C} 30 \mathrm{~s}$ and $72{ }^{\circ} \mathrm{C} 30 \mathrm{~s}$ ). Primer sequences, fragment size and GeneBank accession numbers are shown in Table 1.

\section{Statistical analysis}

Data were analyzed using the SigmaStat (Jandel Scientific, San Rafael, CA, USA) software package. One-way ANOVA (followed by multiple pair-wise comparisons using Tukey test) was used for the analysis of TL differences between groups.

\section{Discussion}

Telomerase-dependent mechanisms cannot explain the telomere lengthening occurring in the absence of telomerase (Liu et al. 2007) and the observed effects of spermatozoa TL in that of the offspring. Herein, we report that spermatozoa TL determine the TL of early embryos before telomerase is expressed and, thereby, likely by an alternative lengthening of telomeres (ALT) (Bryan et al. 1995) where spermatozoa telomeres may act as guide. The epigenetic dynamics of preimplantation development provide a favorable landscape for ALT. The methylation levels of the oocyte genome are substantially lower than in somatic cells (Kobayashi et al. 2012, Smith et al. 2012) and an intense active demethylation occurs in the paternal genome after fertilization (Wossidlo et al. 2011), providing a low DNA methylation environment ideal for ALT (Gonzalo et al. 2006).

As TL seems to be inherited mostly from the paternal side (Unryn et al. 2005, De Meyer et al. 2007, Njajou et al. 2007, Kimura et al. 2008, Eisenberg et al. 2012), spermatozoon telomeres should play a predominant role on the recombination mechanism compared with oocyte telomeres, but the reason for this paternal-specific $\mathrm{TL}$ inheritance remains unclear. The longer TL observed in spermatozoa compared with oocytes can explain the exclusively paternal effect, as the paternally inherited telomeres could be used as a template or guide to lengthen the shorter maternally inherited telomeres during ALT. In agreement, oocytes telomeres were previously found to be surprisingly short compared with somatic cells (Liu et al. 2007). In contrast, another article reported longer TL for oocytes and female pronuclei compared with spermatozoa and male pronuclei (Turner \& Hartshorne 2013). A possible cause for the discrepancies is that TL analysis in the later report was performed by $\mathrm{qFISH}$ and thereby the results may have been influenced by differences in hybridization efficiency due to the very distinct chromatin conformation in male and female gametes, especially when taking into account that metaphase plates cannot be obtained from gametes or pronuclea. Supporting this idea, sperm TL quantified by qFISH (Turner \& Hartshorne 2013) are half of those obtained using telomere restriction fragment (TRF) analysis (Kozik et al. 1998, Baird et al. 2006, Kimura et al. 2008, Pickett et al. 2011). In further agreement with the notion of oocyte telomere being shorter than those of the spermatozoon, we observed that TL was shorter in parthenotes compared with those obtained by fertilization with Mus musculus. In the same trend, another article showed a shorter TL in parthenogenetic Mus musculus embryos compared to fertilized embryos when qPCR was employed, whereas qFISH yielded inconsistent results depending on the strain (Liu et al. 2007).

The precise mechanism by which spermatozoa telomere plays a direct role in embryonic TL remains unclear. It is tempting to think that spermatozoon telomeres serve as a template for lengthen oocyte's telomeres during syngamia, but a recent report refutes this idea: using a transgenic mouse model with tagged telomeres, the authors observed that the tag was transmitted to the offspring following a Mendelian 
inheritance. This observation proves that telomeres are not copied from one chromosome to its homologous counterpart in the germline or preimplantation embryos as it occurs by ALT in somatic cells (Neumann et al. 2013). Thus, it seems that the ALT occurring in early embryos does not occur inter-telomerically (i.e., by copying the telomere of another chromosome), but intratelomerically (i.e., by using its own sequence as template) (Muntoni et al. 2009), so the spermatozoon telomeres would serve as a guide to determine the final length rather than a template for ALT.

We have observed that the differences in early embryo TL originated from differences in spermatozoa TL were maintained through fetal development. That is, resulting offspring with diverse $T L$ depended on the $T L$ of the spermatozoa from which they were conceived. The offspring from older mice displayed a lower TL compared with that from younger mice, in agreement with the differences in spermatozoa TL. Similarly, the offspring from Mus spretus males exhibited shorter telomeres than that from Mus musculus. However, in the latter case, we acknowledge that although the differences observed at the two-cell stage are only dependent on spermatozoa TL, the differences observed later, after the onset of embryonic telomerase expression, may have been influenced by possible differences in activity or expression between Mus musculus and Mus spretus telomerases. Further support for the major role of spermatozoa TL in offspring TL comes from a study of TERT haploinsufficiency in mice, where the restoration of TERT was not able to restore $\mathrm{TL}$ in the offspring, thereby suggesting that other factors, such as sperm TL, determined the offspring TL (Chiang et al. 2010).

In conclusion, we provide evidence for a direct role of spermatozoa telomeres in the telomerase-independent telomere lengthening taking place during preimplantation development, where spermatozoa telomeres seem to act as guides for intra-telomeric ALT of the oocyte telomeres. The differences originated before the onset of telomerase expression are not compensated later in development and persist after birth, thereby providing a mechanistic explanation for the paternally mediated inheritance of TL observed in human studies.

\section{Declaration of interest}

The authors declare that there is no conflict of interest that could be perceived as prejudicing the impartiality of the research reported.

\section{Funding}

This work was funded by Grants AGL2012-39652-C02-01, AGL2012-37510, RYC-2012-10193 and AGL2014-58739-R from the Spanish Ministry of Economy and Competitiveness.
C de Frutos was supported by a fellowship from INIA (Spain) and N F Balvís by a FPI Grant from the Spanish Ministry of Economy and Competitiveness.

\section{References}

Allsopp RC, Vaziri H, Patterson C, Goldstein S, Younglai EV, Futcher AB, Greider CW \& Harley CB 1992 Telomere length predicts replicative capacity of human fibroblasts. PNAS 89 10114-10118. (doi:10.1073/ pnas.89.21.10114)

Armanios M \& Blackburn EH 2012 The telomere syndromes. Nature Reviews. Genetics 13 693-704. (doi:10.1038/nrg3246)

Atzmon G, Cho M, Cawthon RM, Budagov T, Katz M, Yang X, Siegel G, Bergman A, Huffman DM, Schechter CB et al. 2010 Evolution in health and medicine Sackler colloquium: genetic variation in human telomerase is associated with telomere length in Ashkenazi centenarians. PNAS 107 (Suppl 1) 1710-1717. (doi:10.1073/pnas.0906191106)

Baird DM, Britt-Compton B, Rowson J, Amso NN, Gregory L \& Kipling D 2006 Telomere instability in the male germline. Human Molecular Genetics 15 45-51. (doi:10.1093/hmg/ddi424)

Bermejo-Alvarez P, Rizos D, Rath D, Lonergan P \& Gutierrez-Adan A 2008 Epigenetic differences between male and female bovine blastocysts produced in vitro. Physiological Genomics 32 264-272. (doi:10.1152/ physiolgenomics.00234.2007)

Bryan TM, Englezou A, Gupta J, Bacchetti S \& Reddel RR 1995 Telomere elongation in immortal human cells without detectable telomerase activity. EMBO Journal 14 4240-4248.

Calado R \& Young N 2012 Telomeres in disease. F1000 Medicine Reports 4 8. (doi:10.3410/M4-8)

Cawthon RM 2002 Telomere measurement by quantitative PCR. Nucleic Acids Research 30 e47. (doi:10.1093/nar/30.10.e47)

Chiang YJ, Calado RT, Hathcock KS, Lansdorp PM, Young NS \& Hodes RJ 2010 Telomere length is inherited with resetting of the telomere set-point. PNAS 107 10148-10153. (doi:10.1073/pnas.0913125107)

Daniali L, Benetos A, Susser E, Kark JD, Labat C, Kimura M, Desai K, Granick M \& Aviv A 2013 Telomeres shorten at equivalent rates in somatic tissues of adults. Nature Communications 4 1597. (doi:10. 1038/ncomms2602)

de Lange T 2005 Shelterin: the protein complex that shapes and safeguards human telomeres. Genes and Development 19 2100-2110. (doi:10. 1101/gad.1346005)

De Meyer T, Rietzschel ER, De Buyzere ML, De Bacquer D, Van Criekinge W, De Backer GG, Gillebert TC, Van Oostveldt P \& Bekaert S 2007 Paternal age at birth is an important determinant of offspring telomere length. Human Molecular Genetics 16 3097-3102. (doi:10.1093/hmg/ddm271)

Eisenberg DT, Hayes MG \& Kuzawa CW 2012 Delayed paternal age of reproduction in humans is associated with longer telomeres across two generations of descendants. PNAS 109 10251-10256. (doi:10.1073/ pnas.1202092109)

Gonzalo S, Jaco I, Fraga MF, Chen T, Li E, Esteller M \& Blasco MA 2006 DNA methyltransferases control telomere length and telomere recombination in mammalian cells. Nature Cell Biology 8 416-424. (doi:10. 1038/ncb1386)

Heiss NS, Knight SW, Vulliamy TJ, Klauck SM, Wiemann S, Mason PJ, Poustka A \& Dokal I 1998 X-linked dyskeratosis congenita is caused by mutations in a highly conserved gene with putative nucleolar functions. Nature Genetics 19 32-38. (doi:10.1038/ng0598-32)

Kimura M, Cherkas LF, Kato BS, Demissie S, Hjelmborg JB, Brimacombe M, Cupples A, Hunkin JL, Gardner JP, Lu X et al. 2008 Offspring's leukocyte telomere length, paternal age, and telomere elongation in sperm. PLoS Genetics 4 e37. (doi:10.1371/journal.pgen.0040037)

Kipling D \& Cooke HJ 1990 Hypervariable ultra-long telomeres in mice. Nature 347 400-402. (doi:10.1038/347400a0)

Kishigami S \& Wakayama T 2007 Efficient strontium-induced activation of mouse oocytes in standard culture media by chelating calcium. Journal of Reproduction and Development 53 1207-1215. (doi:10. 1262/jrd.19067)

Kobayashi H, Sakurai T, Imai M, Takahashi N, Fukuda A, Yayoi O, Sato S, Nakabayashi K, Hata K, Sotomaru Y et al. 2012 Contribution of 
intragenic DNA methylation in mouse gametic DNA methylomes to establish oocyte-specific heritable marks. PLoS Genetics 8 e1002440. (doi:10.1371/journal.pgen.1002440)

Kozik A, Bradbury EM \& Zalensky A 1998 Increased telomere size in sperm cells of mammals with long terminal (TTAGGG)n arrays. Molecular Reproduction and Development 51 98-104. (doi:10.1002/(SICI)10982795(199809)51:1 <98::AID-MRD12>3.0.CO;2-Q)

Liu L, Bailey S, Okuka M, Muñoz P, Li C, Zhou L, Wu C, Czerwiec E, Sandler L, Seyfang A et al. 2007 Telemore lengthening early in development. Nature Cell Biology 9 1436-1441. (doi:10.1038/ncb1664)

Martín-Coello J, González R, Crespo C, Gomendio M \& Roldan ER 2008 Superovulation and in vitro oocyte maturation in three species of mice (Mus musculus Mus spretus and Mus spicilegus). Theriogenology 70 1004-1013. (doi:10.1016/j.theriogenology.2008.06.002)

Mourkioti F, Kustan J, Kraft P, Day JW, Zhao MM, Kost-Alimova M, Protopopov A, Depinho RA, Bernstein D, Meeker AK et al. 2013 Role of telomere dysfunction in cardiac failure in Duchenne muscular dystrophy. Nature Cell Biology 15 895-904. (doi:10.1038/ncb2790)

Muntoni A, Neumann AA, Hills M \& Reddel RR 2009 Telomere elongation involves intra-molecular DNA replication in cells utilizing alternative lengthening of telomeres. Human Molecular Genetics 18 1017-1027. (doi:10.1093/hmg/ddn436)

Neumann AA, Watson CM, Noble JR, Pickett HA, Tam PP \& Reddel RR 2013 Alternative lengthening of telomeres in normal mammalian somatic cells. Genes and Development 27 18-23. (doi:10.1101/gad.205062.112)

Njajou OT, Cawthon RM, Damcott CM, Wu SH, Ott S, Garant MJ, Blackburn EH, Mitchell BD, Shuldiner AR \& Hsueh WC 2007 Telomere length is paternally inherited and is associated with parental lifespan. PNAS 104 12135-12139. (doi:10.1073/pnas.0702703104)

Oeseburg H, de Boer RA, van Gilst WH \& van der Harst P 2010 Telomere biology in healthy aging and disease. Pflügers Archiv: European Journal of Physiology 459 259-268. (doi:10.1007/s00424-009-0728-1)

Pickett HA, Henson JD, Au AY, Neumann AA \& Reddel RR 2011 Normal mammalian cells negatively regulate telomere length by telomere trimming. Human Molecular Genetics 20 4684-4692. (doi:10.1093/ hmg/ddr402)
Quinn P, Kerin JF \& Warnes GM 1985 Improved pregnancy rate in human in vitro fertilization with the use of a medium based on the composition of human tubal fluid. Fertility and Sterility $4 \mathbf{4} 493-498$.

Schaetzlein S, Lucas-Hahn A, Lemme E, Kues WA, Dorsch M, Manns MP, Niemann H \& Rudolph KL 2004 Telomere length is reset during early mammalian embryogenesis. PNAS 101 8034-8038. (doi:10.1073/pnas. 0402400101)

Schmittgen TD \& Livak KJ 2008 Analyzing real-time PCR data by the comparative C(T) method. Nature Protocols 3 1101-1108. (doi:10.1038/ nprot.2008.73)

Smith ZD, Chan MM, Mikkelsen TS, Gu H, Gnirke A, Regev A \& Meissner A 2012 A unique regulatory phase of DNA methylation in the early mammalian embryo. Nature 484 339-344. (doi:10.1038/ nature10960)

Starling JA, Maule J, Hastie ND \& Allshire RC 1990 Extensive telomere repeat arrays in mouse are hypervariable. Nucleic Acids Research 18 6881-6888. (doi:10.1093/nar/18.23.6881)

Turner S \& Hartshorne GM 2013 Telomere lengths in human pronuclei, oocytes and spermatozoa. Molecular Human Reproduction 19 510-518. (doi:10.1093/molehr/gat021)

Unryn BM, Cook LS \& Riabowol KT 2005 Paternal age is positively linked to telomere length of children. Aging Cell 4 97-101. (doi:10.1111/j.14749728.2005.00144.x)

Wossidlo M, Nakamura T, Lepikhov K, Marques CJ, Zakhartchenko V, Boiani M, Arand J, Nakano T, Reik W \& Walter J 2011 5Hydroxymethylcytosine in the mammalian zygote is linked with epigenetic reprogramming. Nature Communications 2 241. (doi:10. 1038/ncomms1240)

Received 15 August 2015

First decision 16 September 2015

Revised manuscript received 30 September 2015

Accepted 16 October 2015 